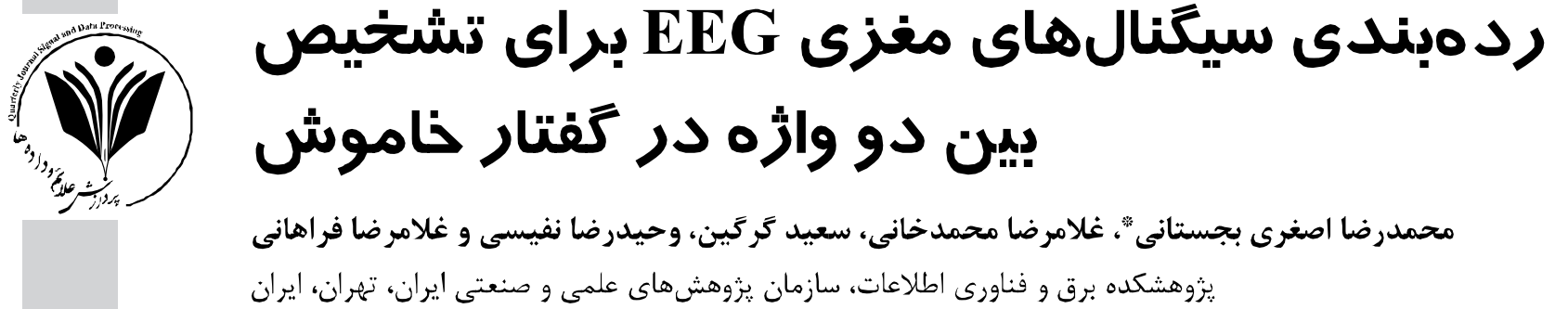

جكيده در اين يزوهش، يكى رابط مغز -رايانه در كاربرد مكالمهُ خاموش براى شناسايى و تفكيك بين دو وازٌه يِيادهسازى شده است. در طى آزمايش،

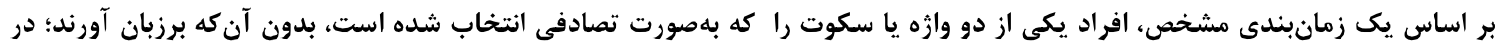

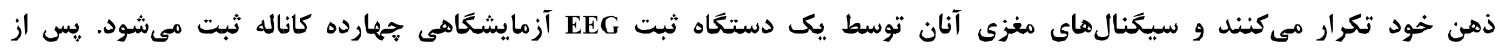

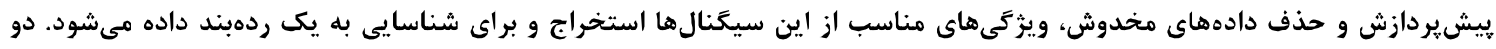

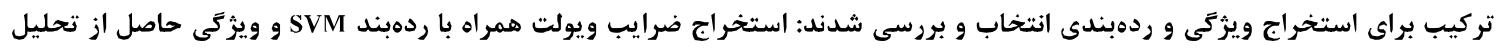

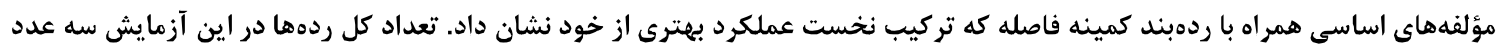

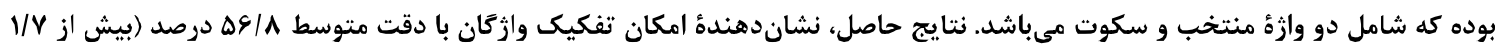

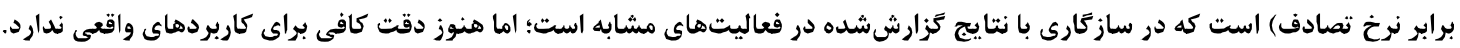
وازگًان كليدى: مكالمه خاموش، رابط مغز -رايانه، تصور كفتار ، سيكنال هاى مغزى.

\title{
Classification of EEG Signals for Discrimination of Two Imagined Words
}

\author{
Mohammad Reza Asghari Bejestani*, Gholam Reza Mohammadkhani, Saeed Gorgin, \\ Vahid Reza Nafisi \& Ghaolam Reza Farahani \\ Iranian Rescarch Organization for Science and Technology (IROST), Tehran, Iran
}

\begin{abstract}
In this study, a Brain-Computer Interface (BCI) in Silent-Talk application was implemented. The goal was an electroencephalograph (EEG) classifier for three different classes including two imagined words (Man and Red) and the silence. During the experiment, subjects were requested to silently repeat one of the two words or do nothing in a pre-selected random order. EEG signals were recorded by a 14 channel EMOTIV wireless headset. Two combinations of features and classifiers were used: Discrete Wavelet Transform (DWT) features with Support Vector Machine (SVM) classifier and Principle Component Analysis (PCA) features with a Minimum-Distance classifier. Both combinations were capable of discriminating between the three classes much better than the chance level (33.3\%), none of them was reliable and accurate enough for a real application though. The first method (DWT+SVM) showed better results. In this case, feature set was D2, D3, D4 and A4 coefficients of 4-level DWT decomposition of the EEG signals, roughly corresponding to major frequency bands (Delta, Theta, Alpha and Beta) of these signals. Three binary SVM machines were used. Each machine was trained to classify between two of the three classes, namely Man/Red, Man/Silence or Red/Silence. Majority Selection Rule was used to determine final class. Once two of these classifiers presented the true class, a win (correct classification) was counted, otherwise a loss (false classification) was

* Corresponding author

$$
\text { * *ويسنده عهدهدار مكاتبات }
$$
\end{abstract}


considered. Finally, Monte-Carlo Cross Validation showed an overall performance of about 56.8\% correct classification which is comparable with the results reported for similar experiments.

\section{Keywords: Silent Talk, Imagined Speech, EEG signals, Classification, Brain-Computer interface}

$$
\begin{aligned}
& \text { ارتباط نفر به نفر از طريق كدگشايى سيگنالهاى مغزى }
\end{aligned}
$$

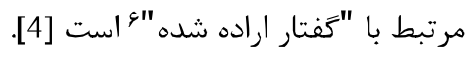

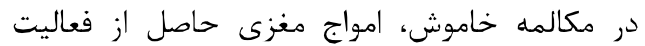

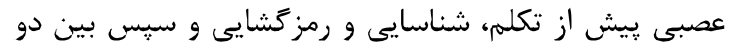

$$
\text { نفر مبادله ميىشود. }
$$

كاربردىترين فعاليتهاى انجامگرفته در اين زمينه

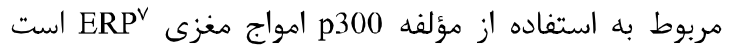

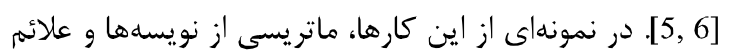

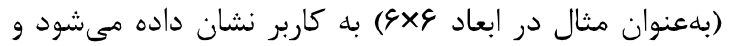

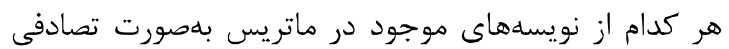

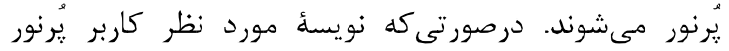

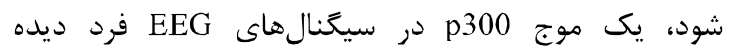
مىشود كه از اين طريق نويسُٔ مورد نظر او شناسايى

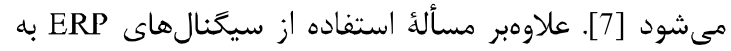
جاى فعاليت عصبى مرتبط با كفتار ارادهشده، مشكل اين روشها سرعت خيلى كم آنها است كه سرعتى در حد جن جند

$$
\text { نويسه در دقيقه را فراهم مي كنئد. }
$$

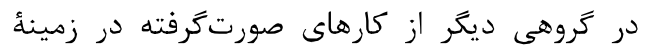

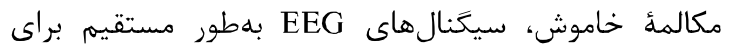
شناسايى كفتار تصورشده استفاده شدهاند. برخلاف روشهوني مبتنى بر مؤلفه

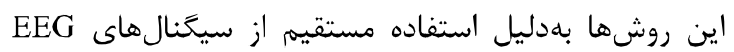
سرعت بالايیى دارند؛ ولى ميزان دقت دستي ديافته از آنها ريايين و به همين دليل تا كنون مطالعه روى آنها به موارد بسيار

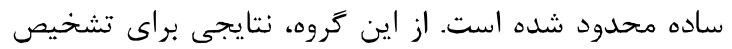
بين دو سيلاب [19,9]، تشخيص بين حروف صدا دار انخَليسى [10, 11] يا تفكيك دو مفهوم [12] كَزارش شده است. همجنين كاربردهايى مثل تشخيص گوينده [13] و و آهنگ تكرار صداها [14, 15] نيز توسط روشنين تهاى مشابه ييادهسازى شدهاند. در [16] آزمايشى مربوط به تشني تشخيص

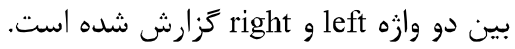

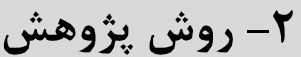

موضوع يزوهش، يِيادهسازى يك BCI در كاربرد مكالمه

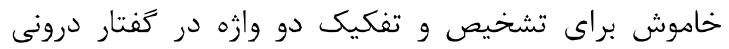
است. دو وازٔه Man و Red براى اين منظور روى افراد

${ }^{6}$ Intended/Imagined speech

${ }^{7}$ Event-Related Potential

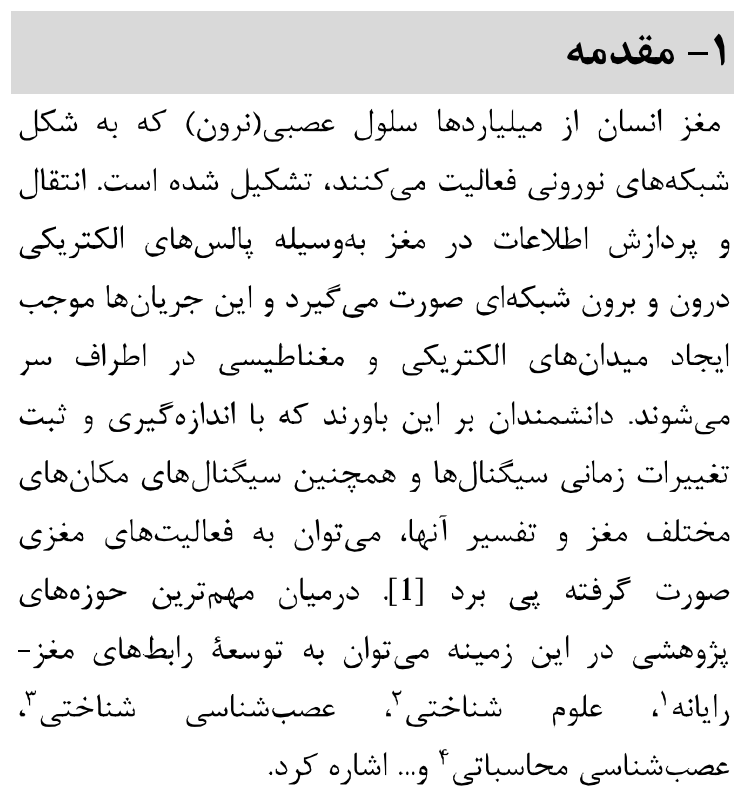

رابطهاى مغز-رايانه بلهنبال يافتن كانال ارتباطى ونى

مستقيم بين مغز و رايانه هستند تا از اين طريق توانايى كنترل يك وسيله بيرونى را بهطورمستقيم از طريق سيخنالهاى مغزى هيسر سازند. اين وسايل سيخنالهاى ناشى از فعاليت عصبها را ترفته و آنها به فعاليتهايى كه كاربر در نظر دارد ترجمه مى كنند [2].

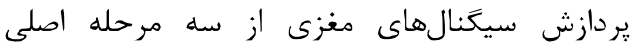
تشكيل شدهاست: 1 - اخذ سيخنال هاى مغزى ب- پيردازش و استخراج ويثگىى ب- الكوريتم ترجمه. در مرحله اخذ سيكنال، ميدانهاى الكتريكى يا مغناطيسى هغز ثبت و به سامانه

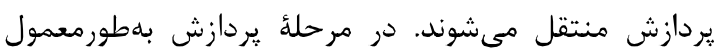
نوفههاى موجود در سيخنال حذف شده، سيخنال هاى با باند فركانسى مورد نظر از سيگنال اصلى استخراج و سيس ويزگى هاى مفيد سيخنال محاسبه مىشود. در مرحلة آخر نيز با استفاده از الكوريتم ترجمه، فعاليتهاى مغزى مرتبط شناسايى و طبقهبندى مىشوند [1-3]. مكالمه خاموش ْيكى از يروزههاى كاربردى در زمينه ييادهسازى رابطهاى مغز-رايانه است كه فعاليتهاى زيادى را در سالهاى اخير برانخيخته است. هدف اين يروزه ايجاد

\footnotetext{
1 Brain-Computer Interface

${ }^{2}$ Cognitive science

${ }^{3}$ Cognitive neuroscience

${ }^{4}$ Computational neuroscience

${ }^{5}$ Silent talk
} 
كفتنى است كه در صورت بلكارگيرى دستخاه EEG

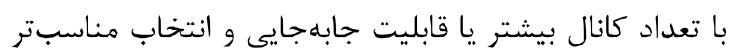

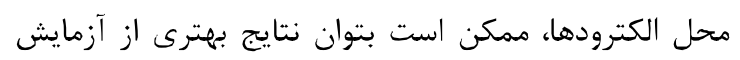

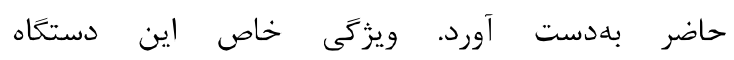
دردسترسبودن، قيمت مناسب و بهكاركيرى آسان آن است.

\section{r-r - شرح آزمايش}

روند آزمايش در شكل (r) نشان داده شده است. فرد مورد آنس

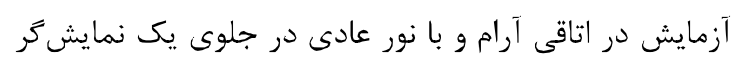

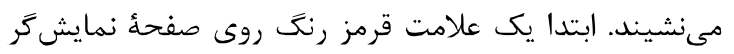

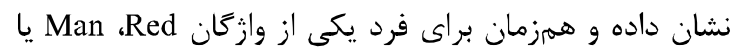

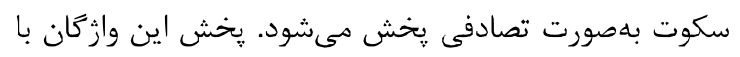

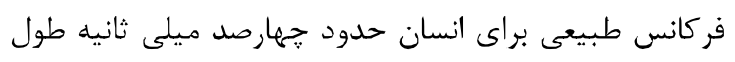

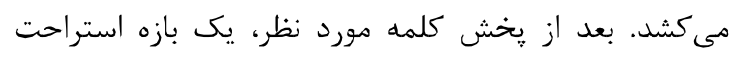

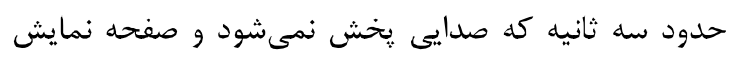

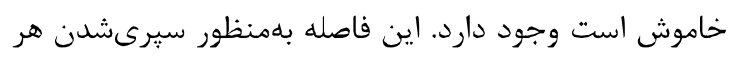

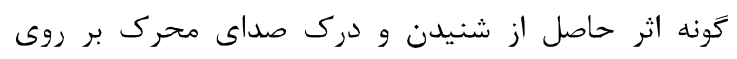

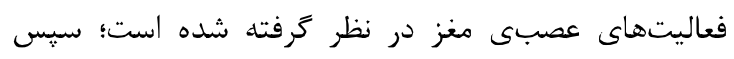

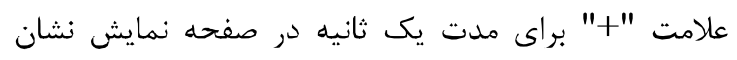

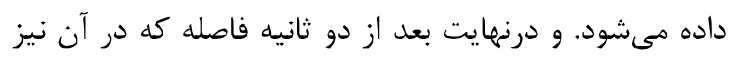

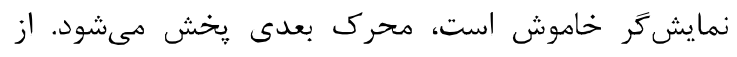

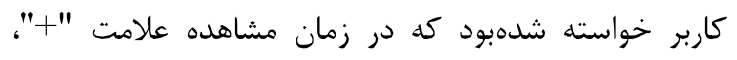

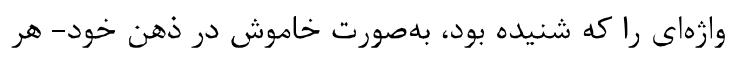
جند بار كه مىتواند- تكرار كند.

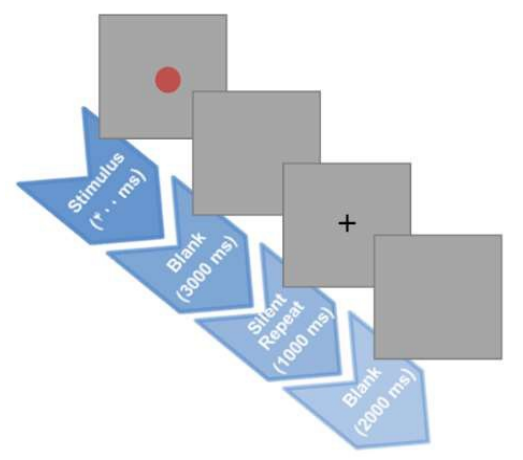

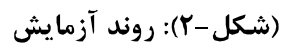

(Figure-2): Experiment timeline

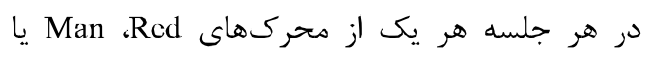

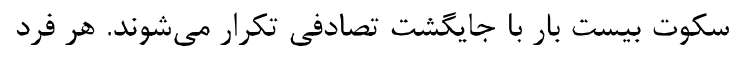
در سه جلسه جداكانه (هر جلسه درمجموع شصت تكايكت تكرار)

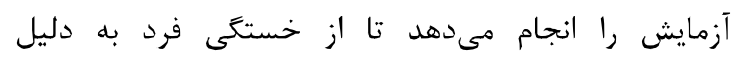

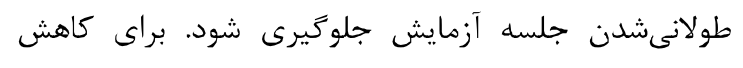

فارسىزبان بررسى شده است. هر دوى اين وازئان

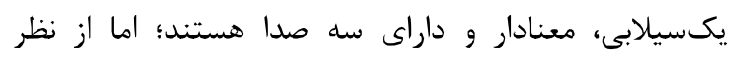

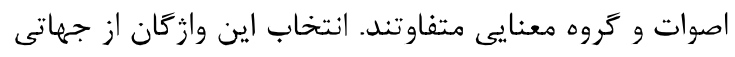

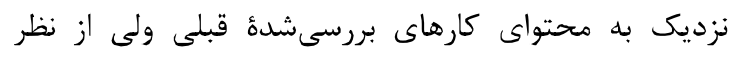

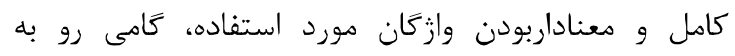

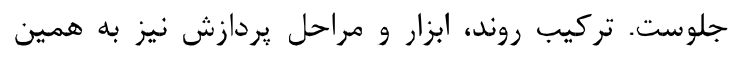

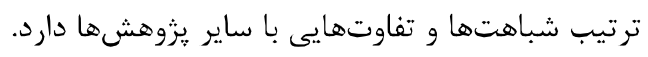

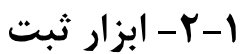

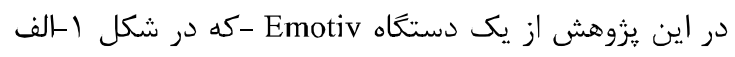

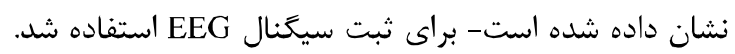

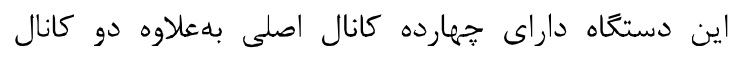

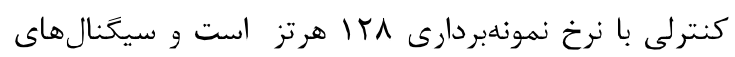

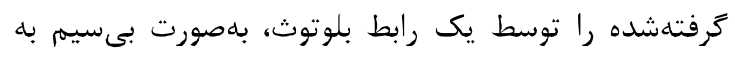

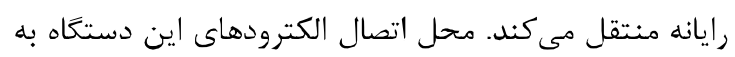

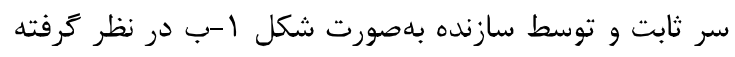

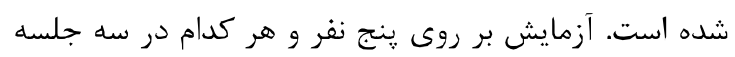

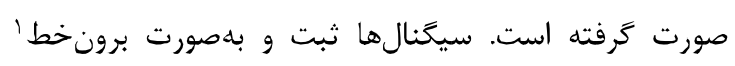

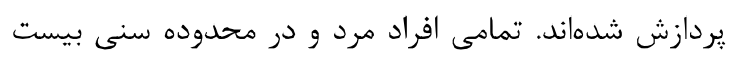

$$
\text { تا سى سال بودهاند. }
$$
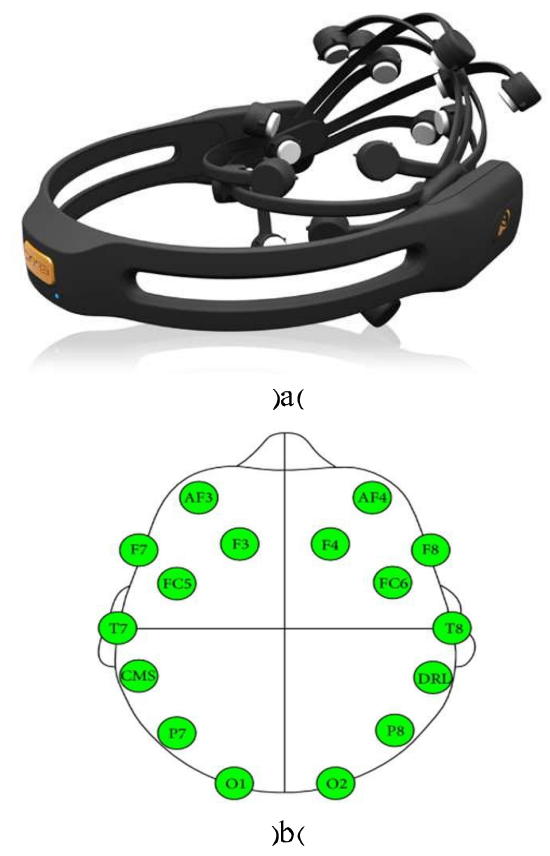

(شكل - (): دستكاه ثبت (a) Emotiv شكل ظاهرى (b) محل

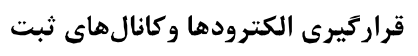

(Figure-1): EMOTIV EEG signal recorder. (a) The headset, (b) designed electrode positions

\section{${ }^{1}$ off line}


مخدوش فرض شده و از جرخهُ يردازش حذف خواهد شد.

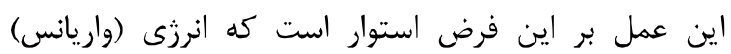

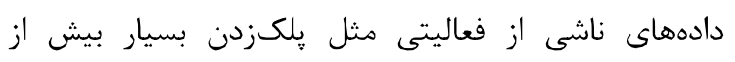

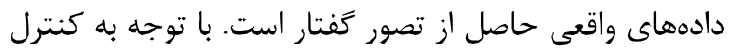

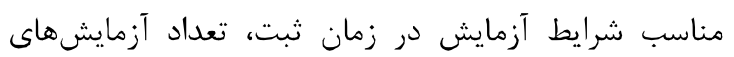

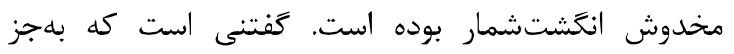

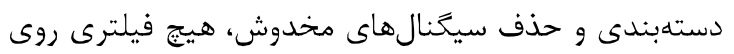

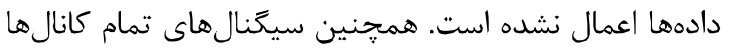
در ردهبندى شركت داده شدهاند.

\section{F-r-r استخراج ويثزى و طبقهبندى}

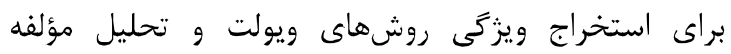

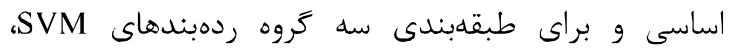

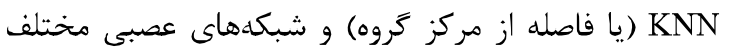

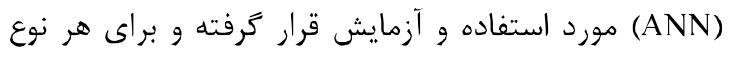

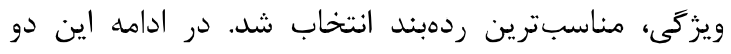

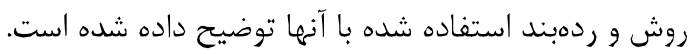

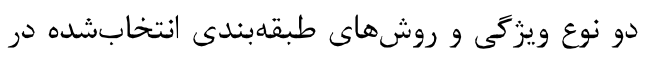
اينجا از سادهترين و رايجترين روشها در زمينهُ يردازش

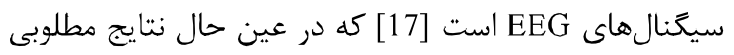

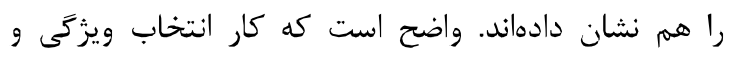

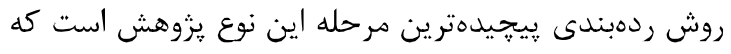

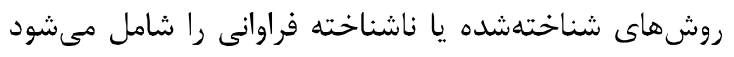

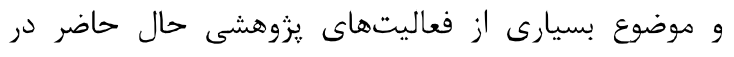

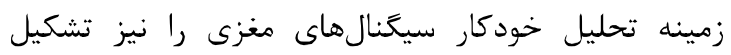

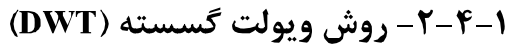

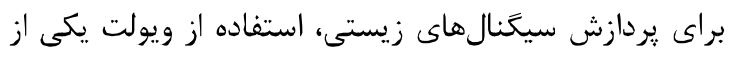

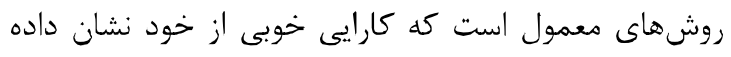

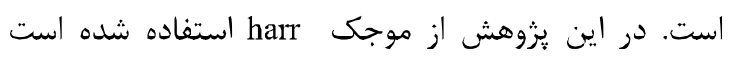

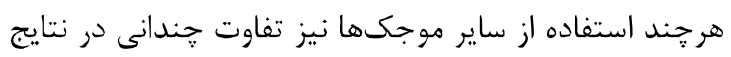

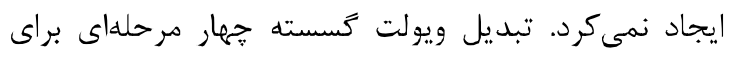

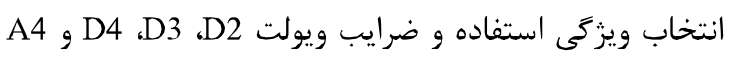

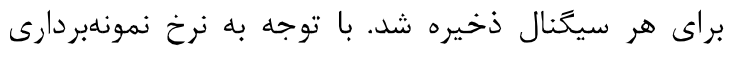

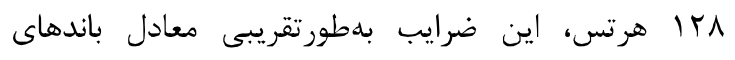

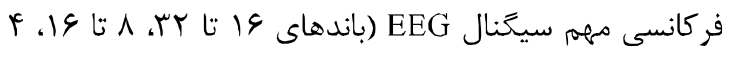

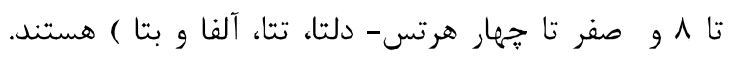

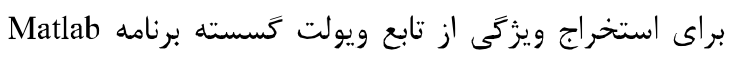

نوفه از كاربرها خواسته شده بود تا حد امكان، يلكزدن يا

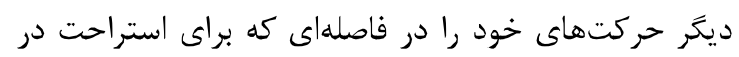
نظر كرفته شده است، انجام دهند.

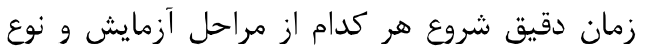

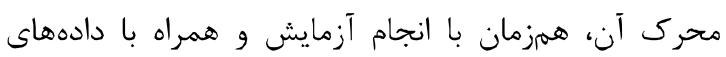

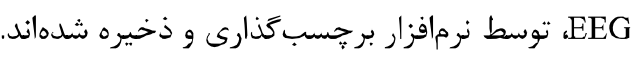

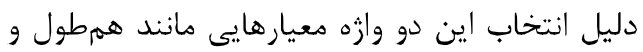

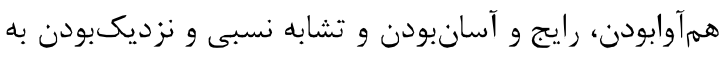

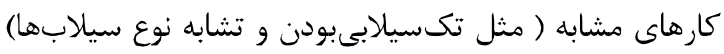

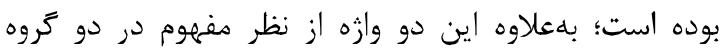

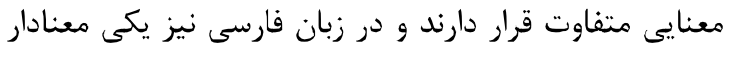
و ديخرى بى معناست.

\section{r-r- - ي -}

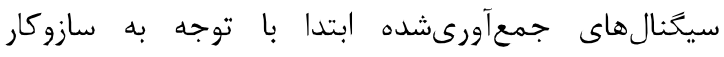

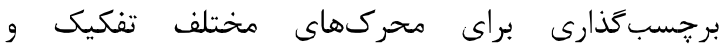

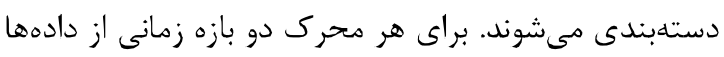

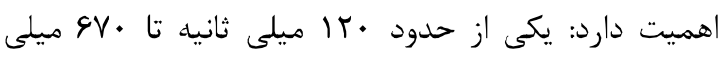

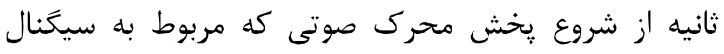

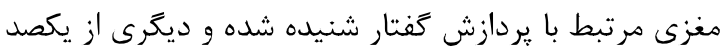

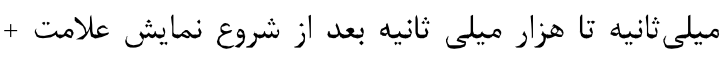

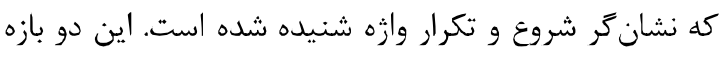

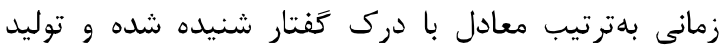
كفتار خاموش در مغز هستند.

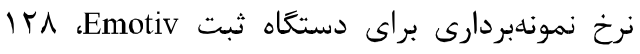

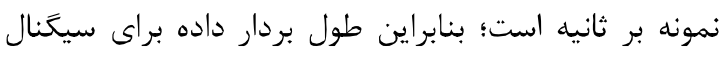

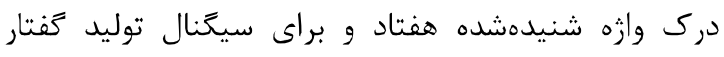

$$
\text { خاموش } 110 \text { ال خواهد بود. }
$$

به اين ترتيب دادكان مورد استفاده شامل سه

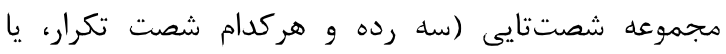

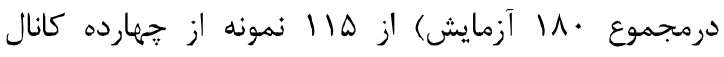
سيخنالهاى EEG براى هر كدام از آزمايششوندكان بوده

با توجه به احتمال وجود دادههاى مخدوش در

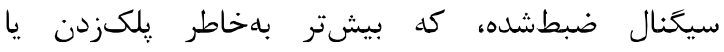

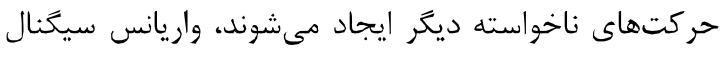
هركانال در هر آزمايش با متوسط واريانس سيكان سيخنال همان

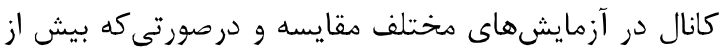

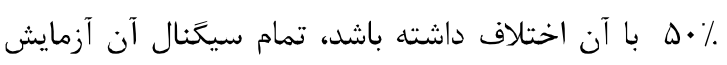


با توجه به وجود حالت سكوت علاوهبر دو وازئ مورد

آزمايش، درواقع ردهبندى بين سه رده انجام گرفتته و نرخ

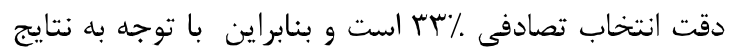

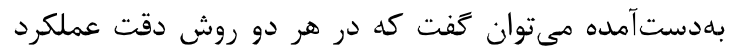

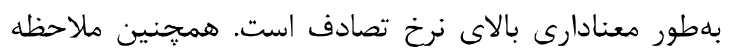

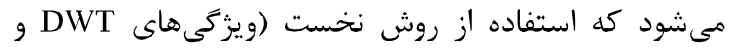
طبقهبند SVM) نتايج بهترى نسبت به روش روش دوف دوم ايجاد

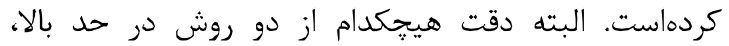

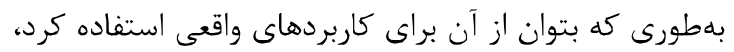

\section{F - مقايسه و نتيجه}

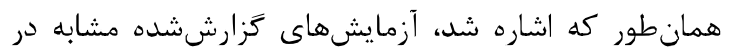

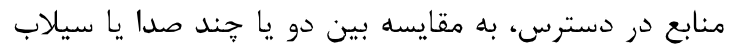

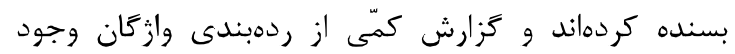

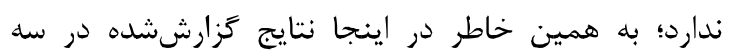

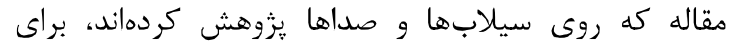
مقايسه آورده مى مقود.

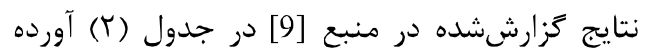

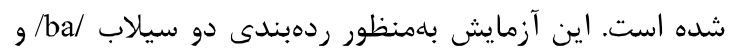

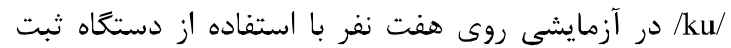
EEG شده است.

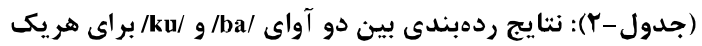

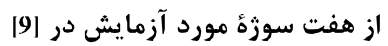

(Table-2): Average classification accuracy (/ba/ or /ku/) for each of the 7 subjects in [9].

\begin{tabular}{|c|c|c|}
\hline & نرخ طبقهبندى & تعداد آزمايش \\
\hline سوزه 1 & $\Delta S$ & 10 \\
\hline سوزه r & $\Lambda$ & 11 \\
\hline سورةه r & - & r \\
\hline سورة F & 14 & Tו \\
\hline سوره هـ & $V \Delta$ & rF \\
\hline سوزه & 11 & ir \\
\hline Vورة V V V V V & $9 V$ & $\Lambda$ \\
\hline متوسط تمام سوزهها & GN/AF & $\Lambda r$ \\
\hline
\end{tabular}

مقاله [18] به مسألله تفكيك سيكنالهاى مربوط به

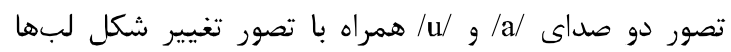

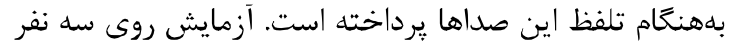

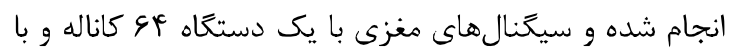

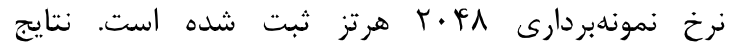

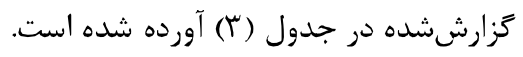

استفاده شده است. بعد از اينكه بردار ويزگى با استفاده از اين روش ايجاد شد، از ردهبند SVM خطى براى ردهبندى

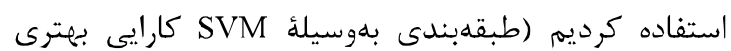
براى دادههاى ثبتشده فراهم ميىكرد). براى جداسازى سه به

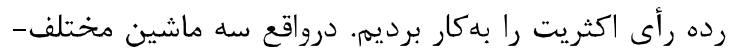

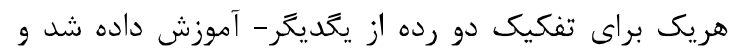

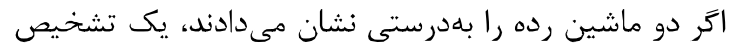
درست و در غير اين صورت يك تشخيص نادرست محاسبه شده است.

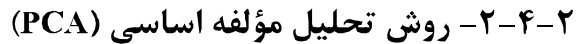

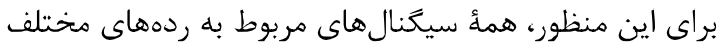

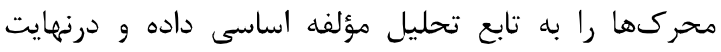

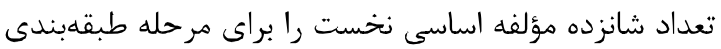
(بر اساس حداقل فاصله) انتخاب كرديم. تعداد شانزده مؤلفه

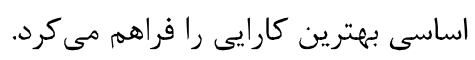

\section{ب- بتايج آزمايش}

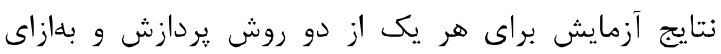

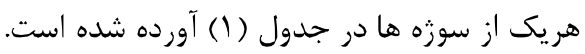

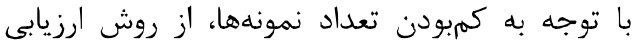

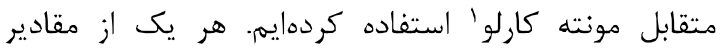
ذكرشده در جدول (1)، متوسط دقت بلدستآهده از خندين

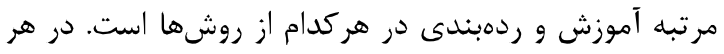

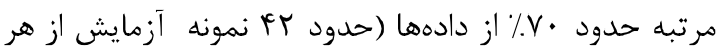

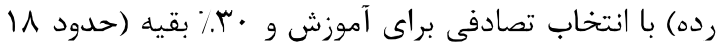
نمونه) براى ردهبندى بهكار برده شدهاند. مقدار انحراف معيار

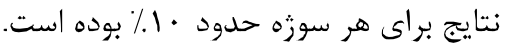

(جدول-1): دقت ردهبندى به در صد بين تمام ردهها بهازاى هر

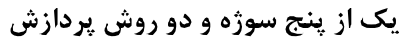

(Table-1): Percent of correct classifications for each subject and each processing method

\begin{tabular}{|c|c|c|}
\hline روش بردازش & DWT & PCA \\
\hline سوزه 1 & fF & FV \\
\hline سوزه r & $\Delta V$ & DI \\
\hline سوزه r & $\Delta F$ & Fr \\
\hline سوزه f & $8 \wedge$ & $\Delta \cdot$ \\
\hline سوزم ها & 91 & $\Delta \Delta$ \\
\hline متوسط تمام سوزهها & $\Delta s / \Lambda$ & $p q / r$ \\
\hline
\end{tabular}

\footnotetext{
${ }^{1}$ Monte-Carlo Cross Validation
} 
(جدول -ه): دقت عملكرد ردهبند LDA در ها طبقهبنلى دو به

دوى ينج رده آوايى براى ينج سوزه [11]

(Table-5): LDA classification performance for 15 pairwise classifications of 5 articulation classes for 5 subjects. [11]

\begin{tabular}{|c|c|c|c|c|c|c|}
\hline & Subject & Tongue & Nasal & Lips & Fricative & Relax \\
\hline \multirow{5}{*}{ Jaw } & $\mathrm{A}$ & $68.0,61.5$ & $73.2,59.4$ & $72.4,62.0$ & $73.7,63.0$ & $71.9,68.8$ \\
\hline & B & $66.9,58.6$ & $70.1,62.2$ & $69.6,60.7$ & $71.8,60.4$ & $73,7,68.8$ \\
\hline & C & $73.2,63.7$ & $71,3,61,6$ & $74.5,59,7$ & $75.2,60.5$ & $73.9,62.4$ \\
\hline & D & $71.7,60.7$ & $69.8,60.7$ & $73.0,60.7$ & $74.8,61.2$ & 70.8 .61 .9 \\
\hline & $\mathrm{E}$ & 70.9 .62 .9 & $71.6,65.4$ & $72.4,62.4$ & $69.8,66.4$ & $72.1,70.3$ \\
\hline \multirow{5}{*}{ Tongue } & $\mathrm{A}$ & \multirow{5}{*}{ - } & 67.7 .65 .6 & $75.3,62.2$ & 74.0 .66 .4 & 72.1 .69 .5 \\
\hline & B & & $71.2,62.8$ & $70.9,56.5$ & $67,1,61,3$ & $70.5,63.7$ \\
\hline & C & & $74.0,64.7$ & $71,3,58.9$ & $75.8,62.1$ & $70.6,61.8$ \\
\hline & D & & 70.2 .62 .6 & 72.2 .57 .7 & $74.6,57.0$ & $69.1,60.5$ \\
\hline & E & & $76.0,66.1$ & $69,7,65,0$ & $70,6,68.2$ & $72.3,63.6$ \\
\hline \multirow{5}{*}{ Nasal } & $\mathrm{A}$ & \multirow{5}{*}{ - } & \multirow{5}{*}{ - } & $72.1,58.3$ & $72.1,68.0$ & $72.1,65.1$ \\
\hline & B & & & $69.3,58.6$ & $72.1,64.0$ & $70.6,67.0$ \\
\hline & C & & & $72.6,61.1$ & $73.6,58.4$ & $72.1,63.2$ \\
\hline & D & & & $66.4,59.1$ & $71.5,59.8$ & $70.3,59.1$ \\
\hline & E & & & $73.7,66.1$ & $71.0,67.8$ & $72.9,68.7$ \\
\hline \multirow{5}{*}{ Lips } & $A$ & \multirow{5}{*}{ - } & \multirow{5}{*}{ - } & \multirow{5}{*}{ - } & $68.8,62.8$ & $75.5,69.0$ \\
\hline & B & & & & $69.6,62.2$ & $68.1,62.8$ \\
\hline & c & & & & $74.8,64.5$ & $69,0,60.0$ \\
\hline & D & & & & $73.1,60.3$ & $69.5,57.7$ \\
\hline & E & & & & $72.5,68.0$ & $70.5,68.9$ \\
\hline \multirow{4}{*}{ Fricative } & A & \multirow{4}{*}{ - } & \multirow{4}{*}{ - } & \multirow{4}{*}{ - } & \multirow{4}{*}{ - } & $75,5,69.0$ \\
\hline & B & & & & & $74.3,65.8$ \\
\hline & c & & & & & $71,0,64.5$ \\
\hline & $\begin{array}{l}\text { D } \\
E\end{array}$ & & & & & $\begin{array}{l}72.8,59.8 \\
71,5,66.6\end{array}$ \\
\hline
\end{tabular}

همانطور كه ملاحظه مىشود نتايج بهدستآمده از

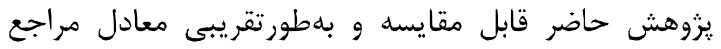

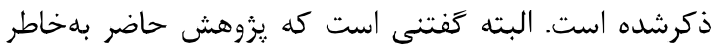

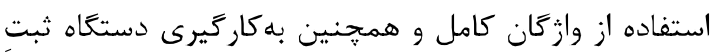

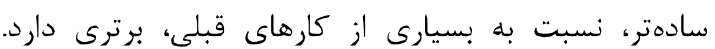
استفاده از سه وازه، هم در ثبت و همم در تفكيك دادهها وجها تمايز اصلى اين يزوهش است. نتايج حاصل، اكر خه دقت كافى برائ براى بهكاركيرى

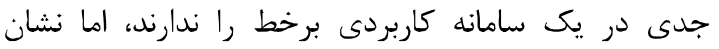
مىدهند كه هدف مكالمه خاموش، با صرف تلاش و انرزى درى

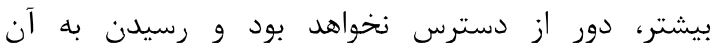
امكان بذير است. - است

\section{5- References}

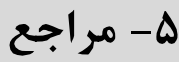

[1] N. Birbaumer and L. G. Cohen, "Braincomputer interfaces: communication and restoration of movement in paralysis", The Journal of physiology, vol. 579, no. 3, pp. 621-636, 2007.

[2] Ivan S. Kotchetkov, Brian Y. Hwang and et. al., "Brain computer Interfaces: military, neurosurgical and ethical prespective", Neurosurg Focus, vol. 28, no. 5, pp. 1-6, 2010.

[3] M. A. Lebedev and M. A. L. Nicolelis, "BrainMachine interfaces: past, present and future", TRENDS in Neurosciences, vol. 29, no. 9, pp. 536-546, 2006.

[4] Defense Advanced Research Projects Agency: Department of Defense Fiscal Year 2010 Budget Estimates Washington, DC, Department of Defense, 2009
(جدول - "r): كارايى تشخيص واكهها براى هر يك از افراد

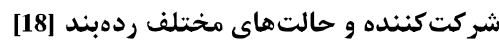

(Table-3): Classification accuracies and standard deviations (rounded \%) for 3 subjects (S1, S2and S3) on 3 pairwise

discriminations and overall.

\begin{tabular}{|c|c|c|c|c|}
\hline & سكوت:/a/ & /سكوت: & $/ \mathbf{u} /: / \mathbf{a} /$ & متوسط \\
\hline سورةه 1 & $r \pm v q$ & $r \pm \lambda r$ & $r \pm V r$ & $\Delta \pm V \wedge$ \\
\hline سوزه r & $\Delta \pm \gamma_{1}$ & $F \pm V T$ & $\Delta \pm q$. & $\vee \pm 9 \Lambda$ \\
\hline سوزه r & $F \pm \varepsilon V$ & $r \pm \Lambda$. & $\varphi \pm \Delta \varphi$ & $M \pm Q \Lambda$ \\
\hline متوسط سه سوزه & VT/MT & VA & GK/GV & $V I / r r$ \\
\hline
\end{tabular}

در [11] نتايج طبقهبندى دوبهدوى ينج رده آوايى

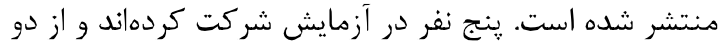

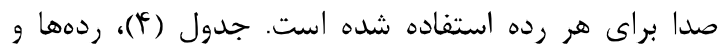
صداهاى مربوط به هر يك را نشان مىدهد.

(جدول-F) : ده نمونه صداى استفادهشده براى

]نج رده آوايى در [11]

(Table-4): The ten indicated phonemes were chosen to contrast five patterns of vocal articulation

(jaw, tongue, nasal, lips and fricative) [11]

\begin{tabular}{l|cll}
\hline $\begin{array}{l}\text { Articulation } \\
\text { class }\end{array}$ & Phoneme & Examples & $\begin{array}{l}\text { Manner of } \\
\text { Production }\end{array}$ \\
\hline Jaw & -aa & saw, jaw & "ah" \\
& -ae & hat, cat & "aeh" \\
Tongue & -1 & light, led & "el" \\
& $-\mathrm{r}$ & right, red & "are" \\
Nasal & $-\mathrm{m}$ & mat, mice & "em" \\
& $-\mathrm{n}$ & net, nice & "en" \\
Lips & - uu & who, drew & "oo" \\
& - ow & boat, over & "oh" \\
Fricative & $-\mathrm{s}$ & same, hiss & s - hissing \\
& $-\mathrm{z}$ & zoo, his & z-buzzing \\
\hline
\end{tabular}

در اين آزمايش دادههاى كاى كانال با نرخ هزار هرتز ثبت و جند ويرّكى مبتنى بر دامنه طيفى فركانس هاى جهار

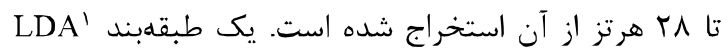

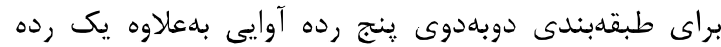

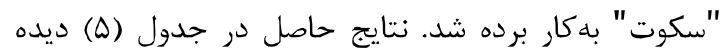

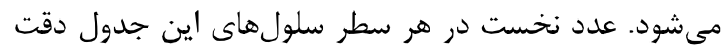

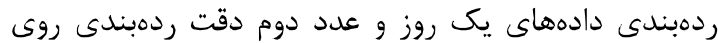
كل دادههاى ثبت شده است. متوسط دقت بهدست دآمده حدود هفتاد درصد براى دادههاى يكى روز و شصت درد درصد براى كل دادكان است.

${ }^{1}$ Linear Discriminant Analysis 
[16] K. Yaser Arafat, S. S. Kanade, "Imagined Speech EEG Signal Processing For Brain Computer Interface", International Journal of Application or Innovation in Engineering \& Management (IJAIEM), Vol. 3, No. 7, pp. 123, 2014.

$$
\begin{aligned}
& \text { [IV] I. شاه بهرامى، ك. نجفى، ط. نجفى. "حوزهاى } \\
& \text { مختلف كاربردى يردازش سيخًال مغزى در ايران ". }
\end{aligned}
$$

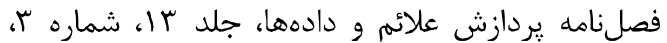

$$
\begin{aligned}
& \text { صفحات و }
\end{aligned}
$$

[17] A. Shahbahrami, K. Nadjafi, T.Nadjafi, "Different Application Fields of Brain Signal Processing", Quarterly Journal of Signal and Data Processing(JSDP), Vol.13, No.3, pp129154, 2016.

[18] C. S. DaSalla, H. Kambara, M. Sato, and Y. Koike, "Single-trial classification of vowel speech imagery using common spatial patterns", Neural Networks, vol. 22, no. 9, pp. 1334-1339, 2009.

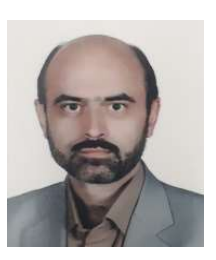
محمدرضا اصغرى بجستانى تحصيلات خود در مقاطع كارشناسى و كارشناسى ارشد مهندسى برق-مخابرات را بهترتيب از دانشخاههاى شيراز و تربيت هدرس برس برس

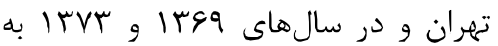
اتمام رسانده و هم اكنون نيز دانشجوى دكتراى تخاى تخصصى همين رشته در سازمان يزّوهشهاى علمى و و صنعتى

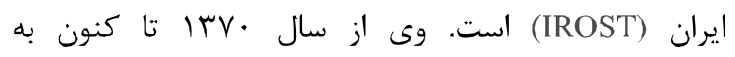
فعاليتهاى آموزشى و يثوهشى در زمينههاى مختلف مرتبط

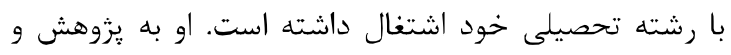

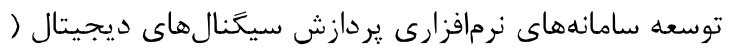
صوت، تصوير، بيولوزيك و ...) علاقهمند است. نشانى رايانامد ايشان عبارت است ازيول

bejestani@irost.ir

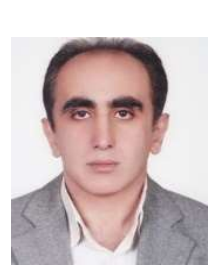

غلامرضا محمدخانى تحصيلات خود رات در مقاطع كارشناسى و كارشناسى ارشد مهندسى برق از دانشعاه صنعتى شريف

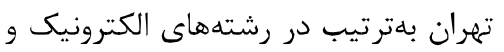

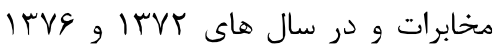
به اتمام رساند. وى از سال تحصيلات خود را در مقطع دكترا در مدرسه عالى (I) ) Ecole National ) مهندسى ENSIL از دانشخاه ليموز (Supérieur d'Ingénieur de Limoges

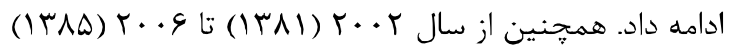

[5] F. Nijboer, E. W. Sellers, J. Mellinger, M. A. Jordan, T. Matuz, $\Lambda$. Furdea, S. Halder, U. Mochty, D. J. Krusienski, and T. M. Vaughan, “A P300-based brain-computer interface for people with amyotrophic lateral sclerosis", Clinical neurophysiology, vol. 119, no. 8, pp. 1909-1916, 2008.

[6] E. Donchin and Y. Arbel, "P300 based brain computer interfaces: a progress report", Foundations of Augmented Cognition, Ncuroergonomics and Operational Neuroscience, pp. 724 $731,2009$.

[7] L. A.Farwell, E.Donchin, "Talking off the top of your head: toward a mental prosthesis utilizing event-related brain potentials", Electroenceph clin Neurophysiol, Vol. 70, pp. 510-523, 1988.

[8] S. Iqbal , Y.U. Khan , O. Farooq," EEG based classification of imagined vowel sounds", 2nd International Conference on Computing for Sustainable Global Development (INDIACom),pp. 1591-1594, IEEE 2015.

[9] K. Brigham, B.V.K.V Kumar, "Imagined Speech Classification with EEG Signals for Silent Communication: A Preliminary Investigation into Synthetic Telepathy", 4th International Conference on Bioinformatics and Biomedical Engineering (iCBBE), pp. 1-4, IEEE 2010.

[10] R. Kamalakkannan, R. Rajkumar, R. M. Madan, D. S. Shenbaga, "Imagined Speech Classification using EEG", Advances in Biomedical Science and Engineering, Vol. 1, No. 2, pp.2032, 2014.

[11] X. Chi, J. B. Hagedorna, D. Schoonovera, and M. D'Zmuraa, "EEG-based discrimination of imagined specch phonemes", International Journal of Bioelectromagnetism, vol. 13, no. 4, 2011.

[12] T. Kim, J. Lee, H. Choi, H. Lee et al., "Meaning based covert speech classification for braincomputer interface based on electroencephalography", 6th International IEEE/EMBS Conference on Neural Engineering (NER), pp. 53$56,2013$.

[13] K. Brigham , B.V.K.V. Kumar, "Subject identification from clectroencephalogram (EEG) signals during imagined speech", Fourth IEEE International Conference on Biometrics: Theory Applications and Systems (BTAS) ,pp. 1-8, 2010.

[14] M. D'Zmura, S. Deng, T. Lappas, S. Thorpe, and R. Srinivasan, "Toward EEG sensing of imagined speech", Human-Computer Interaction New Trends, pp. 40-48, 2009.

[15] S. Deng, R. Srinivasan, T. Lappas, and M. D'Zmura, "EEG classification of imagined syllable rhythm using Hilbert spectrum methods", Journal of neural engineering, vol. 7, no. 4,pp. 046006, 2010. 


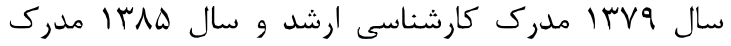

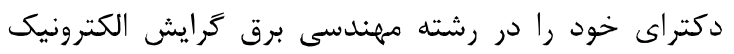

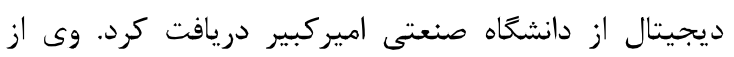

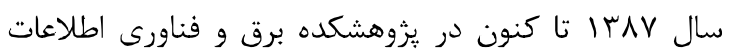

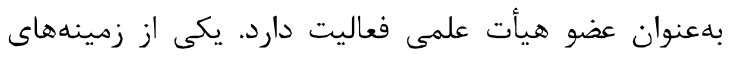
علمى مورد علاقه ايشان يردازش سيخًال (صوت و تصوير)

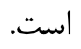
farahani.gh@irost.org

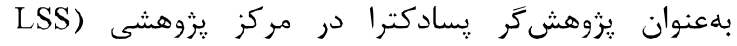
دان ان (Laboratory of Signals and systems ياريس مشغول بهكار بوده است. وى از سال Supelec

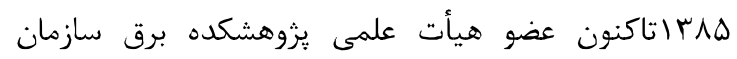

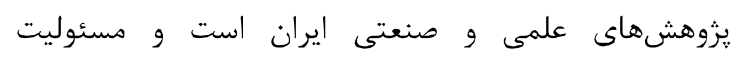

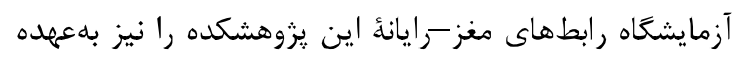

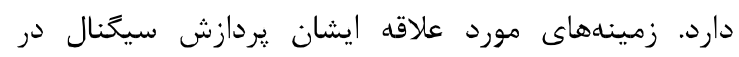
مخابرات ديجيتال و بىسيم است. نشانى رايانامه ايشان عبارت است ازيتا بـ است

\section{mohammadkhani@irost.org}

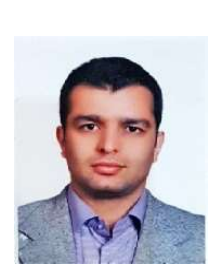

سعيد كركين مدرى كارشناسى و وارسى

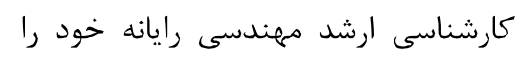

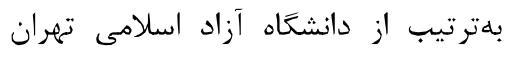

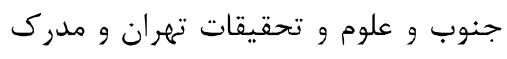
دكترا معمارى رايانه را از دانشكاه شهيد

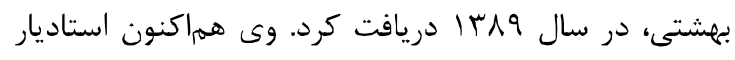

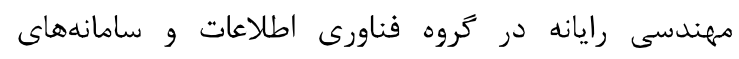

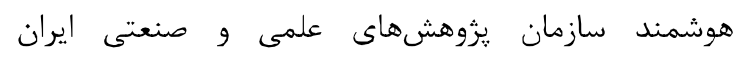
(IROST)

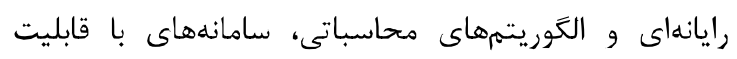

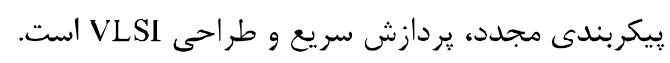
نشانى رايانامه ايشان عبارت است ازئ gorgin@irost.ir

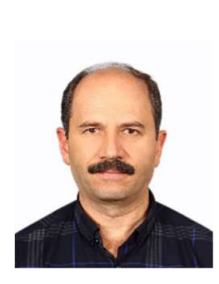

وحيدرضا نفيسى تحصيلات خود را در

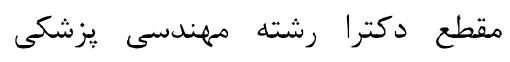

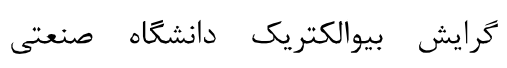

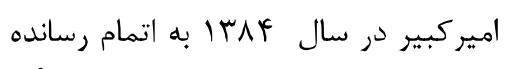

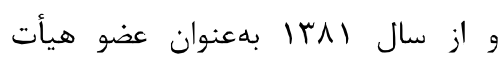

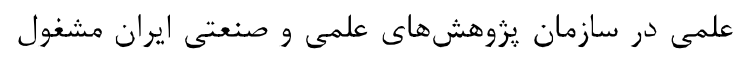

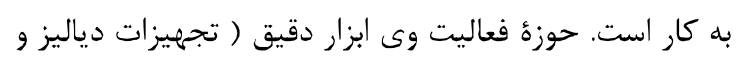

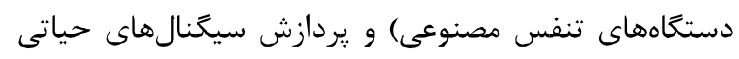
vr_nafisi@irost.org

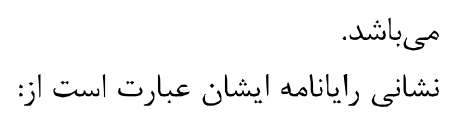

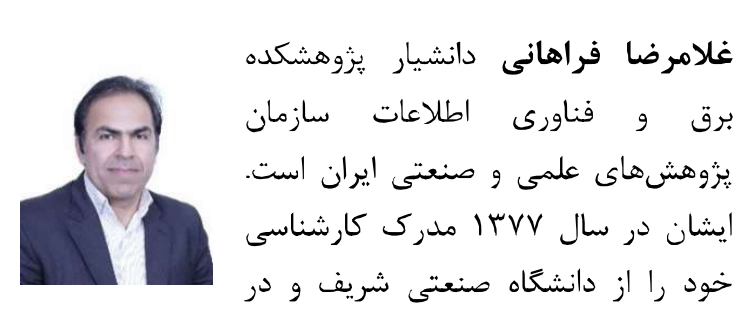

